ARTICLE

DOI: $10.1038 / s 41467-018-05600-y$

\title{
Exceptional electrocatalytic oxygen evolution via tunable charge transfer interactions in $\mathrm{La}_{0.5} \mathrm{Sr}_{1.5} \mathrm{Ni}_{1-x} \mathrm{Fe}_{x} \mathrm{O}_{4 \pm \delta}$ Ruddlesden-Popper oxides
}

Robin P. Forslund1, William G. Hardin' ${ }^{2,7}$, Xi Rong ${ }^{3}$, Artem M. Abakumov, Dmitry Filimonov ${ }^{5}$, Caleb T. Alexander ${ }^{6}$, J. Tyler Mefford ${ }^{1,8}$, Hrishikesh Iyer ${ }^{6}$, Alexie M. Kolpak ${ }^{3}$, Keith P. Johnston ${ }^{6} \&$ Keith J. Stevenson (10 4

The electrolysis of water is of global importance to store renewable energy and the methodical design of next-generation oxygen evolution catalysts requires a greater understanding of the structural and electronic contributions that give rise to increased activities. Herein, we report a series of Ruddlesden-Popper $\mathrm{La}_{0.5} \mathrm{Sr}_{1.5} \mathrm{Ni}_{1-x} \mathrm{Fe}_{x} \mathrm{O}_{4 \pm \delta}$ oxides that promote charge transfer via cross-gap hybridization to enhance electrocatalytic water splitting. Using selective substitution of lanthanum with strontium and nickel with iron to tune the extent to which transition metal and oxygen valence bands hybridize, we demonstrate remarkable catalytic activity of $10 \mathrm{~mA} \mathrm{~cm}^{-2}$ at a $360 \mathrm{mV}$ overpotential and mass activity of $1930 \mathrm{~mA} \mathrm{mg}^{-1}$ ox at $1.63 \mathrm{~V}$ via a mechanism that utilizes lattice oxygen. This work demonstrates that Ruddlesden-Popper materials can be utilized as active catalysts for oxygen evolution through rational design of structural and electronic configurations that are unattainable in many other crystalline metal oxide phases.

\footnotetext{
${ }^{1}$ Department of Chemistry, The University of Texas at Austin, 1 University Station, Austin, TX 78712, USA. ${ }^{2}$ Texas Materials Institute, The University of Texas at Austin, 1 University Station, Austin, TX 78712, USA. ${ }^{3}$ Department of Mechanical Engineering, Massachusetts Institute of Technology, Cambridge, MA 02139, USA. ${ }^{4}$ Center for Electrochemical Energy Storage, Skolkovo Institute of Science and Technology, 3 Nobel Street, Moscow 143026, Russia. ${ }^{5}$ Department of Chemistry, Moscow State University, 1 Leninskiye Gory, Moscow 119991, Russia. ${ }^{6}$ McKetta Department of Chemical Engineering, The University of Texas at Austin, 1 University Station, Austin, TX 78712, USA. ${ }^{7}$ Present address: Exponent Failure Analysis Associates, 9 Strathmore Rd, Natick, MA 01760, USA. ${ }^{8}$ Present address: Department of Materials Science \& Engineering, Stanford University, 496 Lomita Mall, Stanford, CA 94305, USA. These authors contributed equally: Robin P. Forslund, William G. Hardin. Correspondence and requests for materials should be addressed to K.J.S. (email: K.Stevenson@skoltech.ru)
} 
ncreasing global energy demand requires greater efficiency in water electrolyzers to generate hydrogen at a low cost as well as in other devices for energy storage such as rechargeable metal-air batteries. Given that the efficiencies of devices for these types of energy storage are limited largely by the slow kinetics of the oxygen evolution reaction (OER, $4 \mathrm{OH}^{-} \rightarrow \mathrm{O}_{2}+2 \mathrm{H}_{2} \mathrm{O}+4 \mathrm{e}^{-}$), extensive work has been done to reduce the overpotential required to evolve oxygen in basic electrolytes using state-of-theart catalysts ${ }^{1}$. While precious metals such as $\mathrm{Ir}$ and $\mathrm{Ru}$ have become standard OER catalysts when working at low $\mathrm{pH}$, alkaline electrolytes allow for the use of abundant, less expensive metals. For example, $\mathrm{Ni}-\mathrm{M}$ oxyhydroxides such as $\mathrm{Ni}_{1-x} \mathrm{Fe}_{x} \mathrm{OOH}$ are known to be very active for the OER; however, lack of long-range order and uncontrolled electronic structure stemming from different synthetic methods ${ }^{2}$ complicates elucidation of the mechanism(s) by which the OER activity is improved ${ }^{3-5}$. In fact, recent reports question whether $\mathrm{Fe}$ is part of the catalytic cycle or if it promotes partial charge transfer between $\mathrm{Ni}$ and $\mathrm{Fe}$ metal centers $^{2,4,6}$. Additionally, recent work on $\mathrm{Ni}-\mathrm{Fe}$ oxyhydroxides demonstrated that a significant portion of the measured OER current may be due to other processes and highlighted the need for careful electrochemical analysis of what reactions are contributing to the high activities reported ${ }^{7}$. Collectively this means that while $\mathrm{Ni}_{1-x} \mathrm{Fe}_{x} \mathrm{OOH}$ materials have been reported as highly active catalysts, the large variations in electronic configuration and the resulting catalytic activity in these studies complicate establishment of precise structure-property correlations for $\mathrm{Ni}-\mathrm{Fe}$ oxyhydroxides ${ }^{2,5,8}$.

In contrast, perovskite oxides with the nominal formula $\mathrm{ABO}_{3 \pm \delta}$, in which $\mathrm{A}$ is a rare-earth or alkaline earth element and $\mathrm{B}$ is a transition metal, have recently been shown to promote OER catalysis through increased ionic and electronic conductivities, as well as good structural stability and synthetic versatility, all of which enable the development of rational catalyst design criteria $^{9-11}$. Importantly, the ability to substitute elements of varying valence, electronegativity, or ionic size into A- and B-site directly influences the resultant properties of these catalysts ${ }^{1,12}$. An example of this was the substitution of $\mathrm{Cu}$ into the A-site of the quadruple perovskite $\mathrm{CaCu}_{3} \mathrm{Fe}_{4} \mathrm{O}_{12}$ to increase stability of the catalyst $^{13}$. Recently, we demonstrated that highly covalent Co $3 d-\mathrm{O} 2 p$ bonding in $\mathrm{SrCoO}_{2.7}$ improved OER activity via a more energetically favorable lattice oxygen mediated (LOM) reaction pathway, consistent with prior reports and theory ${ }^{14-16}$. This LOM mechanism does not require the redox switching of transition metal sites, but rather utilizes lattice oxygen in the OER when the Fermi level $\left(E_{\mathrm{F}}^{0}\right)$ crosses the transition metal $3 d-\mathrm{O} 2 p$ hybridized bands. This results in ligand holes that activate lattice oxygen which may combine with chemisorbed $\mathrm{OH}$ to produce $\mathrm{O}_{2}-$. This mechanism has since been confirmed by others using isotopic labeling experiments to detect exchanged oxygen from the lattice of $\mathrm{SrCoO}_{3}{ }^{17}$. In a separate report, $\mathrm{SrNiO}_{3}$ perovskite was predicted to be more covalent, even more prone to oxygen deficiency, and thus be more catalytically active than $\mathrm{SrCoO}_{3}{ }^{18}$. Unfortunately, this prediction is hard to validate experimentally as $\mathrm{SrNiO}_{3}$ adopts a non-perovskite structure based on a hexagonal close packing of $\mathrm{Sr}$ and $\mathrm{O}$ atoms ${ }^{19}$. In addition, it is known that the substitution of $\mathrm{Sr}$ into $\mathrm{LaNiO}_{3}$ is limited to $\sim 5-20 \%$ after which phase impurities appear that result in poor catalytic activity $^{20,21}$.

To overcome this limitation, we investigate an alternative crystal structure to the perovskite-phase $\mathrm{SrNiO}_{3}$ that promotes high OER activity but does not suffer from limited Sr solubility and can stabilize highly oxidized, covalently bound Ni. The Ruddlesden-Popper (RP) crystal structure is represented as $\mathrm{A}_{n+1} \mathrm{~B}_{n} \mathrm{O}_{3 n+1}$ or equivalently $(\mathrm{AO})\left(\mathrm{ABO}_{3 \pm \delta}\right)_{n}$, wherein perovskite layers with a thickness of $n\left(\mathrm{BO}_{6}\right)$ octahedra are separated by rocksalt $(\mathrm{AO})(\mathrm{OA})$ double layers. This $\mathrm{RP}$ phase can accommodate all the elemental substitutions available to perovskites as well as additional compositions that are not stable in the perovskite structure $^{22}$. While Ruddlesden-Popper materials have been explored as solid oxide fuel-cell cathodes owing to their chemical flexibility and labile lattice oxygen, they have not been fully examined for room temperature water oxidation ${ }^{23-29}$.

Herein, we report a series of $\mathrm{La}_{0.5} \mathrm{Sr}_{1.5} \mathrm{Ni}_{1-x} \mathrm{Fe}_{x} \mathrm{O}_{4 \pm \delta}$ (LSNF, $x=0$ to 1$)$ OER catalysts that have enabled us to achieve exceptionally high catalytic activities at low overpotentials with small OER Tafel slopes. We show that Sr substitution promotes high catalytic activity by further oxidizing $\mathrm{Ni}$ via charge compensation, enhancing Ni-O covalency and electronic conductivity. Chemical substitution of $\mathrm{Fe}$ for $\mathrm{Ni}$ introduces and tunes the overlap between the $\mathrm{Ni}$ and $\mathrm{Fe} 3 d$ bands and the $\mathrm{O} 2 p$ band. Density functional theory (DFT) modeling confirms that cross-gap hybridization between $e_{g}(\mathrm{Ni}), p(\mathrm{O})$ and $e_{g}(\mathrm{Fe})$ bands across the Fermi level enhances charge transfer interactions across $\mathrm{Fe}-\mathrm{O}-\mathrm{Ni}$ bridges and the bandwidth available for electrode-adsorbate electron transfer. The increased covalency and cross-gap hybridization ${ }^{30}$ of transition metal $3 d$ states and $\mathrm{O} 2 p$ orbitals are an effective new catalyst design criteria for improving OER activity that supports oxygen evolution taking place via the LOM mechanism, a mechanism which has already been demonstrated to apply to other catalyst materials as well. Furthermore, our work illustrates the remarkable catalytic activity of the RP LSNF series that encompasses a range of chemical substitutions and electronic configurations not accessible in other crystalline metal oxide phases and that enables the elucidation of crucial structural-chemical-electronic relationships and the OER mechanism that has not been possible with $\mathrm{Ni}-\mathrm{M}$ oxyhydroxides and other reported metal oxide catalysts for OER.

\section{Results}

Materials characterization. $\mathrm{La}_{0.5} \mathrm{Sr}_{1.5} \mathrm{Ni}_{1-x} \mathrm{Fe}_{x} \mathrm{O}_{4 \pm \delta}$ (LSNF, $x=0$ to 1) samples were synthesized using a modified Pechini method $^{31}$ followed by crystallization and annealing, details of which are found in the Methods section. Electron diffraction and powder X-ray diffraction (PXRD) patterns correspond to a bodycentered tetragonal unit cell with the $I 4 / \mathrm{mmm}$ space group, characteristic of the $n=1$ Ruddlesden-Popper (RP) crystal structure (Figs. 1a, b and Supplementary Figure 1). No superlattice reflections were detected that could be attributed to the $\mathrm{La} /$ $\mathrm{Sr}$ or $\mathrm{Fe} / \mathrm{Ni}$ ordering, ordering of hyperstoichiometric oxygen atoms, or lattice distortions. The $a$ and $c$ unit cell parameters (Fig. 1d) and unit cell volume (Supplementary Figure 2) increase almost linearly with $\mathrm{Fe}$ substitution reflecting that the $\mathrm{La}_{0.5} \mathrm{Sr}_{1.5} \mathrm{Ni}_{1-x} \mathrm{Fe}_{x} \mathrm{O}_{4 \pm \delta}$ solid solution is homogeneous over the entire substitutional range. The $I 4 / \mathrm{mmm}$ structure has been confirmed with Rietveld refinement from PXRD data (Supplementary Table 1, Supplementary Figures 3 and 4). Unit cell volume increases with $\mathrm{Fe}$ substitution are in agreement with the increasing fraction of $\mathrm{Fe}$ cations that have larger ionic radii than Ni cations $\left(r\left(\mathrm{Fe}^{3+}, \mathrm{HS}\right)=0.645 \AA, r\left(\mathrm{Fe}^{4+}, \mathrm{HS}\right)=0.585 \AA, r\left(\mathrm{Ni}^{3+}\right.\right.$, $\left.\mathrm{LS})=0.56 \AA, r\left(\mathrm{Ni}^{4+}, \mathrm{LS}\right)=0.48 \AA\right)^{32}$. The ratio of the apical to equatorial $\mathrm{Ni} / \mathrm{Fe}-\mathrm{O}$ distances increases from 1.038 in LSN to 1.073 in LSF, reflecting slight apical elongation of the $(\mathrm{Ni} / \mathrm{Fe}) \mathrm{O}_{6}$ octahedra. The $14 / \mathrm{mmm}$ crystal structure is also directly viewed with annular bright field scanning transmission electron microscopy (ABF-STEM, Fig. 1c), which visualizes heavier cations and lighter oxygen anions simultaneously. The ABF-STEM image shows perfect stacking of the perovskite $\left(\mathrm{BO}_{2}\right)(\mathrm{B}=\mathrm{Ni}, \mathrm{Fe})$ layers and the rocksalt $(\mathrm{AO})(\mathrm{OA})(\mathrm{A}=\mathrm{La}, \mathrm{Sr})$ layers without stacking faults and the crystal structure propagates to the surface without amorphization. 
a
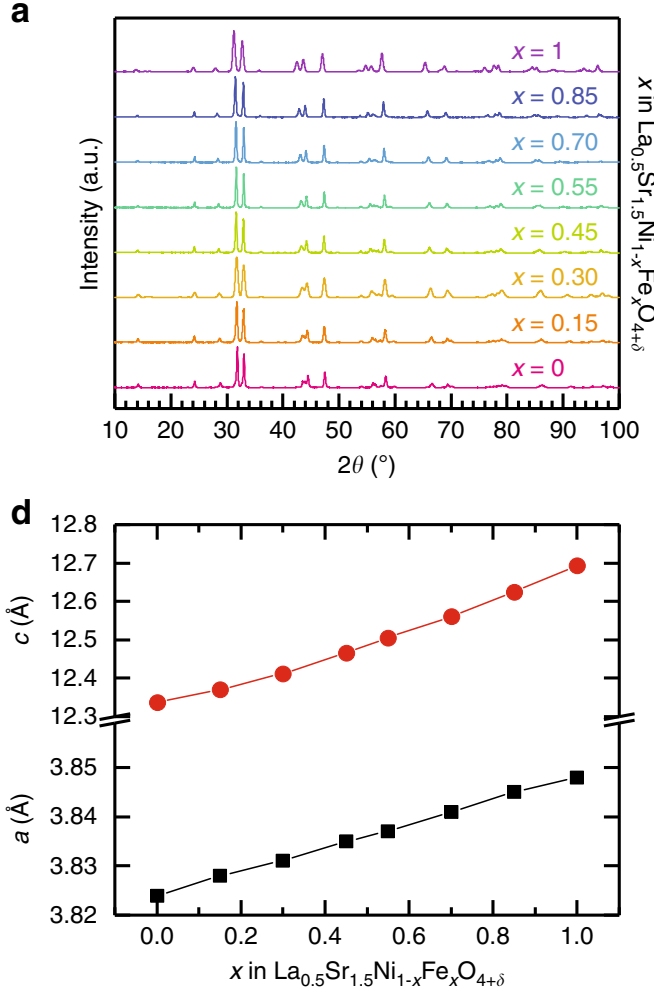

b
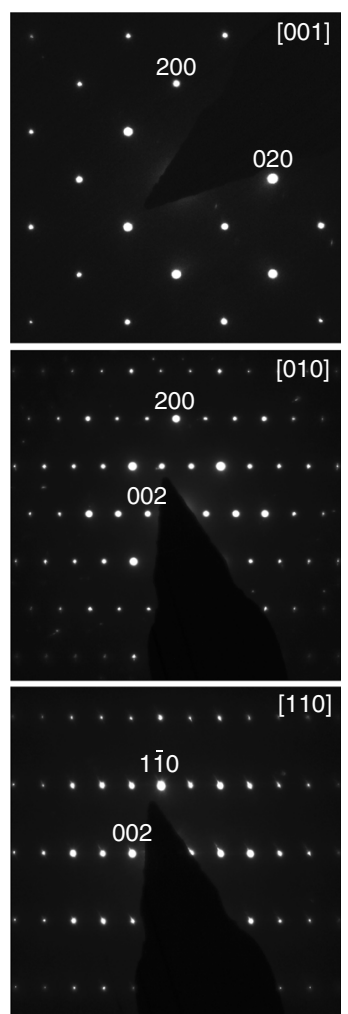

C

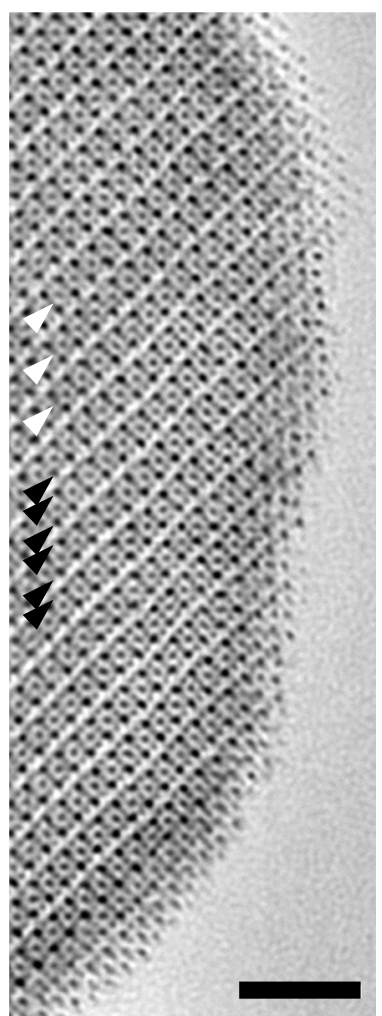

Fig. 1 Crystallographic characterization of the $\mathrm{La}_{0.5} \mathrm{Sr}_{1.5} \mathrm{Ni}_{1-x} \mathrm{Fe}_{x} \mathrm{O}_{4+\delta}$ series. a PXRD patterns of $\mathrm{La}_{0.5} \mathrm{Sr}_{1.5} \mathrm{Ni}_{1-x} \mathrm{Fe}_{x} \mathrm{O}_{4+\delta}$ demonstrate all compositions have the tetragonal $n=1$ Ruddlesden-Popper $14 / \mathrm{mmm}$ structure. $\mathbf{b}$ Electron diffraction patterns of LSNF30 confirm the absence of cation and/or anion ordering. c [100] ABF-STEM image of LSNF30 directly visualizes the stacking of the $\left(\mathrm{BO}_{2}\right)$ octahedra (white arrowheads, $\left.\mathrm{B}=\mathrm{Ni}, \mathrm{Fe}\right)$ and $(\mathrm{AO})(\mathrm{OA})$ layers $($ black arrowheads, $\mathrm{A}=\mathrm{La}, \mathrm{Sr}$ ) in the Ruddlesden-Popper structure. The scale bar is $2 \mathrm{~nm}$. d Compositional dependence of $a$ and $c$ unit cell parameters showing $0 \leq x \leq 1$ homogeneity range

The consistent morphology of catalysts is crucial to the analytical comparison of electrochemical OER activity. Highangle annular dark-field scanning TEM (HAADF-STEM) and Brunauer-Emmet-Teller (BET) surface area analysis were performed and the results, presented in Supplementary Figure 5, indicate similar morphology across the LSNF series regardless of Fe substitution. All compositions consist of 50-300 nm crystallites loosely sintered into agglomerates that are up to several microns in size. This morphological similarity is reinforced by BET surface area results which range from 3.3 to $8.0 \mathrm{~m}^{2} \mathrm{~g}^{-1}$ (Supplementary Figure 6).

Electrochemistry. The $\mathrm{La}_{0.5} \mathrm{Sr}_{1.5} \mathrm{Ni}_{1-x} \mathrm{Fe}_{x} \mathrm{O}_{4 \pm \delta}$ (LNSF) series was supported on Vulcan carbon (VC) at $30 \mathrm{wt} \%$ and tested for the OER with the results presented in Fig. 2. Supporting the catalyst on VC increases the conductivity of the composite by facilitating increased electrical contact between the glassy carbon RDE and the catalyst particles as well as between catalyst particles themselves. While carbon has its limitations as a support for devicelevel applications, the issue of carbon corrosion is a matter of kinetics and for fundamental studies such as this one it is quite common to support metal oxide catalysts on carbon when doing OER studies at room temperature. A major reason for this is to eliminate possible contributions from other supports, such as $\mathrm{Ni}$ foam, that while more appropriate for device-level mass loadings and performance can contribute a great deal to the OER current generated or have their own redox features that can convolute the examination of the material of interest and the fundamental principles explored in this work. The carbon ratio used in this paper was chosen as a result of our past work in which we carefully studied the effect of the catalyst to carbon ratio to determine that a 30:70 weight ratio resulted in optimal catalyst utilization $^{33}$.

Representative polarization curves for all supported compositions are shown in Fig. 2a and Supplementary Figure 7. For all amounts of Fe substitution, except for $100 \%$ (LSF), the onset potential for the OER decreases and the corresponding catalytic activity increases significantly compared to LSN. Merely $15 \%$ replacement of $\mathrm{Ni}$ with $\mathrm{Fe}$ increases the specific activity $(\mathrm{mA} \mathrm{cm}$ -2 oxide) by over an order of magnitude at $1.63 \mathrm{~V}$ vs the reversible hydrogen electrode corrected for electrolyte resistance (RHE-iR) as seen in Fig. 2b. Further substitution of $\mathrm{Fe}$ for $\mathrm{Ni}$ yields a volcano-like catalytic trend with $30 \% \mathrm{Fe}$ substitution in LSNF30 being the most active composition. LSNF30 displays exceptionally high catalytic activities of $32.7 \mathrm{~mA} \mathrm{~cm}^{-2}$ oxide and $1930 \mathrm{~mA} \mathrm{mg}$ ${ }^{-1}{ }_{\text {oxide }}$ at $1.63 \mathrm{~V}$, over 20 and 40 times higher than the respective values for LSN, with a Tafel slope of $44 \mathrm{mV} \mathrm{dec}^{-1}$ and achieves the common benchmark of $10 \mathrm{~mA} \mathrm{~cm}^{-2}$ geo at only a $360 \mathrm{mV}$ overpotential which is remarkable considering the relatively small mass loading used (Fig. 2c). Details regarding conversion of potentials from $\mathrm{Hg} / \mathrm{HgO}$ to $\mathrm{RHE}$ can be found in the Methods and Supplementary Figure 8 . Figure $2 \mathrm{~b}$ and Supplementary Figure 9 demonstrate the significantly higher mass activity of LSNF30 compared to other leading metal oxide OER catalysts with LSNF30 being over five times more active than the recently reported $\mathrm{SrCoO}_{2.7}$ (1930 vs $332 \mathrm{~mA} \mathrm{mg}^{-1}$ oxide) and over an order of magnitude better than $\mathrm{IrO}_{2}\left(173 \mathrm{~mA} \mathrm{mg}{ }^{-1}\right.$ oxide), a leading precious metal oxide benchmark catalyst. The LSNF30 composition generates three times as much current per surface area as 

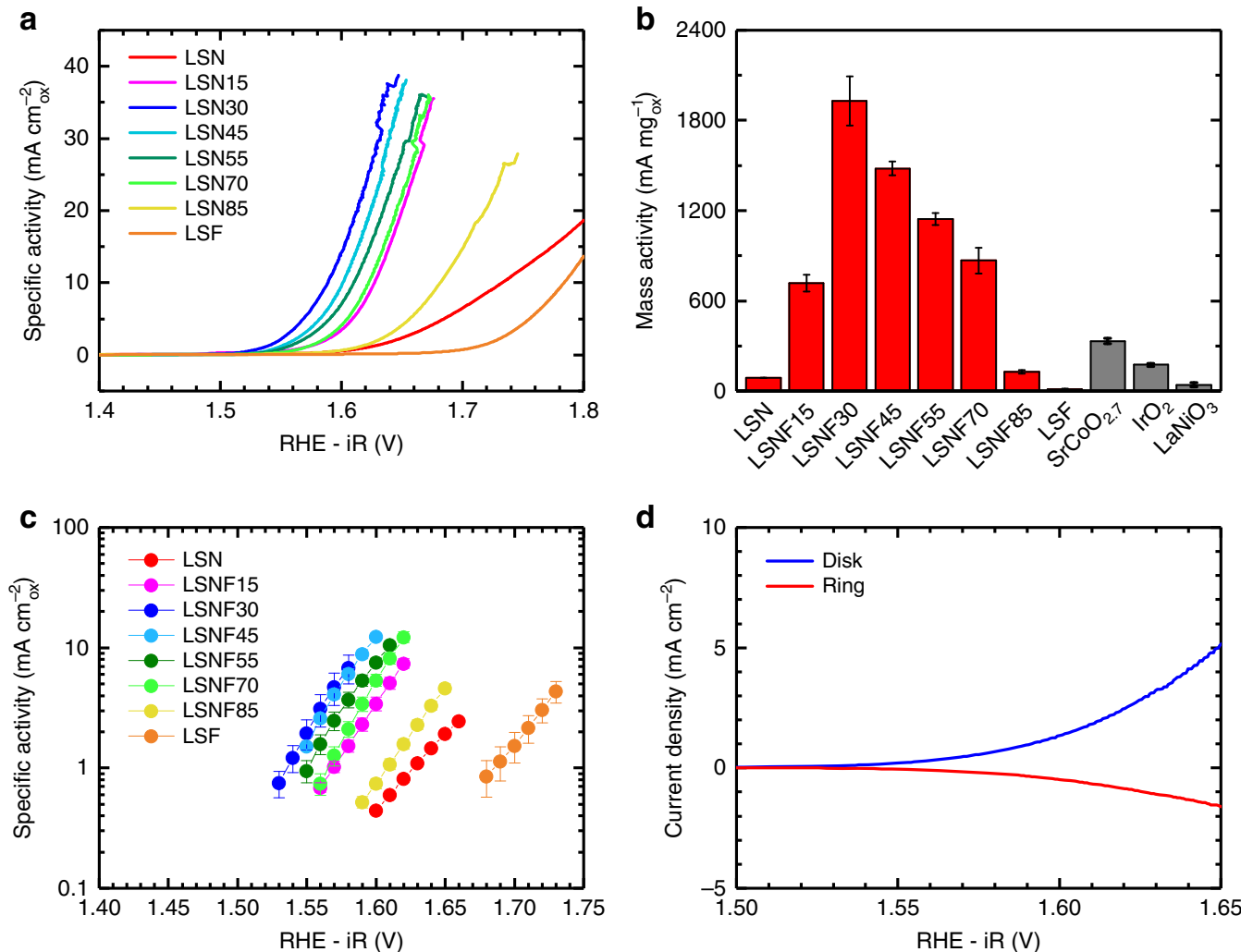

Fig. 2 Oxygen evolution results and catalytic activities for the LSNF series supported at $30 \mathrm{wt} \%$ on XC72 Vulcan carbon (VC). Activities measured in $\mathrm{O}_{2}$-saturated $0.1 \mathrm{M} \mathrm{KOH}$ at $10 \mathrm{mV} \mathrm{s}^{-1}$ and $1600 \mathrm{rpm}$. a Averaged (anodic and cathodic) OER polarization curves presented in geometric current density $\left(5 \mathrm{~mm} \mathrm{GCE}, \mathrm{A}=0.196 \mathrm{~cm}^{2}\right.$ ). b Oxide mass activities of the $\mathrm{LSNF}$ series at $1.63 \mathrm{~V}$ vs $\mathrm{RHE}-\mathrm{iR}$ compared to leading $\mathrm{OER}_{\mathrm{catalysts}} \mathrm{SrCoO}_{2.7}, \mathrm{LaNiO}_{3}$, and IrO $\mathrm{I}_{2}$ on VC, all tested in the same experimental setup and conditions. Error bars are the standard deviations of measurements performed in triplicate. $\mathbf{c}$ Tafel plots of the specific activity of each LSNF catalyst. Error bars are the standard deviations of measurements performed in triplicate $\mathbf{d}$ RRDE test to confirm that current is due to oxygen evolution. The disk has a thin layer of $30 \mathrm{wt} \% \mathrm{LSNF} 30 / \mathrm{VC}$ and the ring is Pt. $\mathrm{O}_{2}$ generated at the disk is then reduced back to $\mathrm{OH}^{-}$at the ring which is poised at $-0.4 \mathrm{~V}$ vs $\mathrm{Hg} / \mathrm{HgO}(1 \mathrm{M})$. The collection efficiency of the RRDE at $1.63 \mathrm{~V}$ was found to be $34 \%$. RRDE measurements were performed in Ar-saturated $0.1 \mathrm{M} \mathrm{KOH}$

$\mathrm{SrCoO}_{2.7}\left(32.7\right.$ vs $9.2 \mathrm{~mA} \mathrm{~cm}^{-2}$ oxide $)$ and over an order of magnitude more than $\mathrm{IrO}_{2}\left(1.2 \mathrm{~mA} \mathrm{~cm}{ }^{-2}\right.$ oxide) at $1.63 \mathrm{~V}$ (Supplementary Table 2). The catalytic activity of VC is negligible, contributing only $7 \mathrm{~mA} \mathrm{mg}^{-1}$ (Supplementary Figures 7 and 9) at $1.63 \mathrm{~V}$. Cyclic voltammetry (CV) experiments using a rotating ring disk electrode (RRDE) were performed to ensure the measured currents for LSNF30VC were due to oxygen evolution and not carbon oxidation or other reactions. As can be seen in Fig. $2 \mathrm{~d}$, at $1.63 \mathrm{~V}$, the same potential at which we base our activity measurements, the measured collection efficiency of $34 \%$ closely matches the theoretical collection efficiency. While carbon corrosion may become a factor at much higher potentials where the VC support would oxidize, at the potentials we use to examine the catalyst in this fundamental context the only current measured is due to oxygen evolution, lending further validity to the trends we observe. Additional experimental details for RRDE experiments can be found in the Methods section and Supplementary Figure 10. In the absence of the VC support, much lower activities were observed (Supplementary Figure 11) due to the lack of a carbon matrix to increase conductivity, however, the same volcano trend in activities was observed across the LSNF series and LSNF30 exhibited catalytic activity comparable to $\mathrm{IrO}_{2}$. Supplementary Table 2 summarizes the catalytic activities of other promising catalysts to enable comparison with LSNF30 using multiple metrics. Examined in the context of both precious and non-precious metal OER catalysts, LSNF30 is one of the most active catalysts ever reported for the OER.
The stability of LSNF30 was investigated using multiple types of electrochemical tests. One such experiment was a galvanostatic current hold during which the supported catalyst sustained 10 $\mathrm{A} \mathrm{g}^{-1}$ ox for over $24 \mathrm{~h}$ without failure (Supplementary Figure 12). To further investigate the stability of the catalyst both supported and unsupported LSNF30 materials were drop cast at $1 \mathrm{mg} \mathrm{cm}-2$ onto Ni foam electrodes and cycled 100 times in $0.1 \mathrm{M} \mathrm{KOH}$. The currents measured at $1.63 \mathrm{~V}$ on the $\mathrm{Ni}$ foam that is capable of performing the OER on its own, both drop cast with VC and without, were subtracted out. As can be seen in Fig. 3 and Supplementary Figure 13 the OER current generated by the LSNF30VC composite stabilizes very quickly and displays a much higher mass activity than the unsupported catalyst due to the added conductivity of the composite that comes from the VC support. These activities are much lower than measured on RDE due to the inefficient catalyst utilization that comes from using higher mass loadings as well as mass transport limitations and the buildup of oxygen on the electrode without rotation. These stability experiments demonstrate that while a small amount of amorphization may occur at the surface during the first CV (Supplementary Figure 14) as a result of wetting or an initial restructuring such has been seen for other perovskite catalysts ${ }^{34}$ and as was seen for the bare Ni foam electrodes, the exceptionally high activities we observe are due to the covalency imparted by Sr substitution into the crystalline RP phase and the stability of the structure with repeated cycling. Were a transformation to amorphous oxyhydroxide phases taking place and governing 

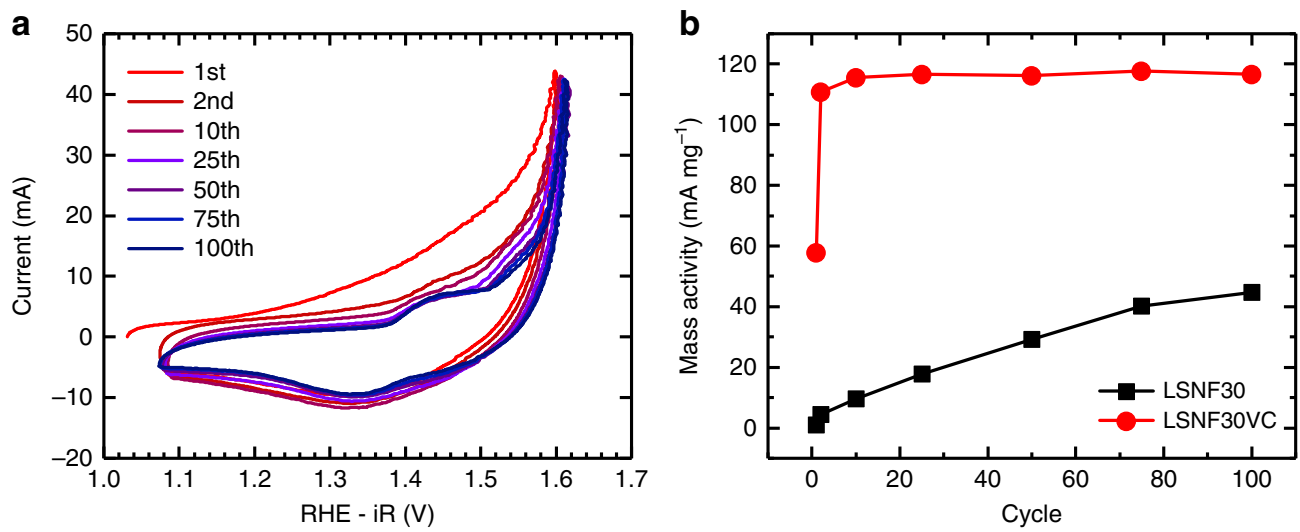

Fig. 3 Cyclic voltammetry stability tests of LSNF30 dropcast on Ni foam electrodes at $1 \mathrm{mg} \mathrm{cm}^{-2}$. a One hundred cycles of LSNF30 supported at 30 wt\% on VC performed in $\mathrm{O}_{2}$-saturated $0.1 \mathrm{M} \mathrm{KOH}$ at $10 \mathrm{mV} \mathrm{s}^{-1}$. b Mass activities measured at $1.63 \mathrm{~V}$ for both LSNF3OVC and unsupported LSNF30 at various points during the 100 cycle stability tests. Mass activities were calculated by subtracting the current at $1.63 \mathrm{~V}$ for an Ni foam electrode with or without carbon but without catalyst from the current measured from the catalyst on Ni foam with or without the VC support and then dividing by the mass of catalyst used
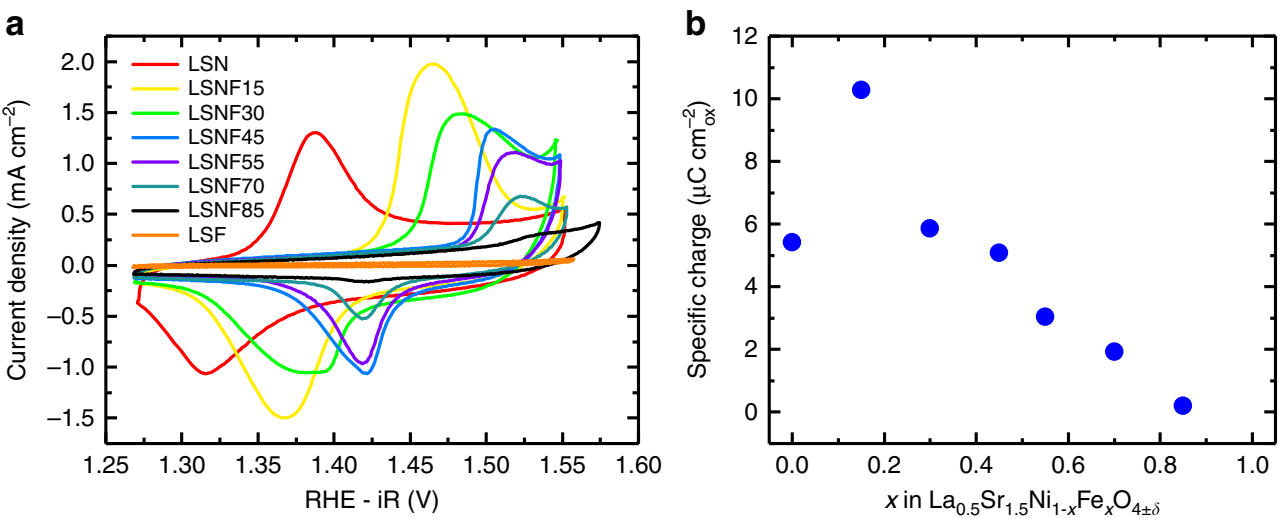

Fig. 4 Cyclic voltammetry (CV) of LSNF catalysts in $\mathrm{O}_{2}$-saturated $0.1 \mathrm{M} \mathrm{KOH}$. a CVs of LSNF at $100 \mathrm{mV} \mathrm{s}^{-1}$ revealing a systematic anodic shift in $\mathrm{Ni}^{2+/ 3+}$ oxidation/intercalation potentials with increasing Fe substitution. $\mathrm{CVs}$ at $100 \mathrm{mV} \mathrm{s}^{-1}$, taken after 3-4 cycles, are depicted to aid the reader in distinguishing peak potential shifts and relative areas, but at $100 \mathrm{mV} \mathrm{s}^{-1}$ contributions to $E_{\mathrm{p}}$ from capacitance and mass transport resistance cannot be ignored. To address this, peak potentials reported in Supplementary Figure $8 \mathrm{c}$ were taken from stable $\mathrm{CVs}$ at $10 \mathrm{mV} \mathrm{s}^{-1}$. b Specific oxidative charge $\left(\mu \mathrm{C} \mathrm{cm}^{-2}\right.$ oxide) resulting from the integration of oxidation waves. Integrations were performed using specific current density $\left(\mu \mathrm{A} \mathrm{cm}{ }^{-2}\right.$ oxide $)$ to normalize differences in catalyst surface area (Supplementary Figure 8d). The OER baselines for stable CVs at $10 \mathrm{mV} \mathrm{s}^{-1}$ were fit and subtracted. Supplementary Figure 14 contains the CVs used for integration

the catalytic activity of the LSNF materials then we would expect much lower currents due to the decreased surface areas of active sites formed at high temperature as well as the majority of oxide mass that is made up of catalytically inactive $\mathrm{La}$ and $\mathrm{Sr}$ sites. The stability of LSNF materials was further studied using DFT and is discussed below.

Chemical states and electronic structure. Upon exposure to alkaline electrolyte the surface of the catalyst is hydroxylated and reduced. The $\mathrm{Ni}^{2+/ 3+}$ redox couple in LSNF is observed to shift to more positive potentials with Fe substitution, indicating a direct modulation of Ni's reactivity with Fe substitution. This redox couple exists in the incipient OER region, as indicated in the reversible CV peaks in Fig. $4 \mathrm{a}$. The potential range over which the redox peaks are observed is consistent with prior studies of $\mathrm{Ni}$-based electrocatalysts ${ }^{3,35,36}$ with $\mathrm{Fe}$ substitution shifting the peak potential $\left(E_{\mathrm{P}}\right)$ of $\mathrm{Ni}^{2+/ 3+}$ oxidation as documented with $\mathrm{Ni}-\mathrm{Fe}$ oxyhydroxides ${ }^{3,4,35}$. Integration of the oxidation waves (Supplementary Figures 15 and 16) reveals that the specific oxidative charge $\left(\mu \mathrm{C} \mathrm{cm}^{-2}\right.$ oxide $)$ transferred during oxidation/ intercalation consistently decreases upon continued replacement of $\mathrm{Ni}$ with $\mathrm{Fe}$, with the exception of the initial introduction of $\mathrm{Fe}$ in LSNF15 (Fig. 4b). Similar behavior was previously reported for $10 \% \mathrm{Fe}$ substitution into $\mathrm{NiOOH}$ hydroxide electrodes ${ }^{3}$ and was speculated to be due to increased oxygen and electrolyte diffusivity. This interpretation is supported here by the increased electrochemical oxygen diffusion rate measured in LSNF15 as compared to LSN $\left(1.04 \mathrm{E}^{-12} \mathrm{~cm}^{2} \mathrm{~s}^{-1}\right.$ vs $8.03 \mathrm{E}^{-13} \mathrm{~cm}^{2} \mathrm{~s}^{-1}$; Supplementary Figure 17 and Supplementary Table 3) and confirms that along with the surface redox of $\mathrm{Ni}^{2+} 3+$, oxygen intercalation concomitant with $\mathrm{Ni}$ redox is likely given the labile nature of oxygen in $\mathrm{La}_{2} \mathrm{NiO}_{4 \pm \delta}$. The observation that the $\mathrm{pH}$ dependence of the $\mathrm{Ni}^{2+/ 3+}$ oxidation $E_{\mathrm{p}}$ in Supplementary Figure 14 behaves like a Nernstian pseudocapacitor using $\mathrm{OH}^{-}$as the intercalating ion further indicates that the intercalation of oxygen is taking place $14,33,37,38$.

It is known that over $50 \%$ Sr substitution for La induces metallike conductivity 25,39 in the charge transfer insulator $\mathrm{La}_{2} \mathrm{NiO}_{4+\delta}$ due to hole doping in the $\mathrm{O} 2 p$ band $^{40}$. Furthermore, the remarkable improvement of the catalytic activity of LSN upon Fe substitution for $\mathrm{Ni}$ may be explained by the impact of the Fe $3 d$ 
Table 1 Oxygen hyperstoichiometry $(\delta)$ and B-site oxidation states in $\mathrm{La}_{0.5} \mathrm{Sr}_{1.5} \mathrm{Ni}_{1-x} \mathrm{Fe}_{\mathbf{x}} \mathrm{O}_{4 \pm \delta}$

LSNF series oxidation state characterization

\begin{tabular}{|c|c|c|c|c|c|c|c|c|c|}
\hline Catalyst & Fe sub. & $\delta$, hyperst. & $\delta$ s.d. & $\mathrm{B}^{+}$avg & $\mathrm{B}^{+}$s.d. & $\mathrm{Fe}^{4+}$ (Moss.) & $\mathrm{Fe}^{3+}$ (Moss.) & $\mathrm{Ni}^{\mathrm{X}+}$ avg & $\mathrm{Ni}^{\mathrm{x}+}$ s.d. \\
\hline LSN & $0 \%$ & 0.018 & 0.013 & 3.54 & 0.03 & - & - & 3.54 & 0.03 \\
\hline LSNF30 & $30 \%$ & 0.042 & 0.010 & 3.58 & 0.02 & $62 \%$ & $38 \%$ & 3.57 & 0.03 \\
\hline LSNF55 & $55 \%$ & 0.088 & 0.011 & 3.68 & 0.02 & $58 \%$ & $42 \%$ & 3.80 & 0.05 \\
\hline LSNF70 & $70 \%$ & 0.076 & 0.022 & 3.65 & 0.04 & $58 \%$ & $42 \%$ & 3.82 & 0.14 \\
\hline LSNF85 & $85 \%$ & 0.081 & 0.036 & 3.66 & 0.07 & $61 \%$ & $39 \%$ & 3.95 & 0.48 \\
\hline LSF & $100 \%$ & 0.143 & 0.037 & 3.79 & 0.07 & $62 \%$ & $38 \%$ & - & - \\
\hline
\end{tabular}

Average B-site oxidation states determined by iodometry, the results of Mössbauer spectroscopy, and the calculated average Ni oxidation state

Supplementary Figures 18 and 19 contain the deconvoluted Mössbauer spectra

states on the electronic structure of LSNF. Earlier studies of the electronic structure of $\mathrm{La}_{1.1} \mathrm{Sr}_{0.9} \mathrm{Ni}_{0.8} \mathrm{Fe}_{0.2} \mathrm{O}_{4 \pm \delta}$ with resonant photoemission spectroscopy suggest that the $\mathrm{Fe} 3 d$ states make a substantial contribution to the valence band near the Fermi level $\left(E_{\mathrm{F}}\right)$ by strongly hybridizing with the $\mathrm{O} 2 p$ and $\mathrm{Ni} 3 d$ states which facilitates cation oxidation and redox processes ${ }^{28}$. The mixed $\mathrm{Fe} 3 d$ and $\mathrm{Ni} 3 d$ bands pinned at $E_{\mathrm{F}}$ in close proximity to the $\mathrm{O} 2 p$ band should give rise to a mixture of $\mathrm{Ni}^{3+/ 4+}$ and $\mathrm{Fe}^{3+/ 4+}$ where the relative proportion of oxidation states changes with the amount of Fe substitution ${ }^{27,29,41}$. This was confirmed by ex situ room temperature Mössbauer spectroscopy (Supplementary Figures 18 and 19, Table 1) in conjunction with iodometric titrations. Knowing the average B-site oxidation state as well as the oxidation state of $\mathrm{Fe}$ allows for the calculation of the Ni oxidation state and Table 1 contains the results of this analysis. The average oxidation state of $\mathrm{Ni}$ increases with increasing $\mathrm{Fe}$ content from +3.54 in LSN to +3.95 in LSN85, as does the oxygen hyperstoichiometry $(\delta)$ and the average B-site oxidation state. The increase in the oxidation state of $\mathrm{Ni}$ is further demonstrated by the observation that the $\mathrm{Ni} 3 p$ spectrum obtained by X-ray photoelectron spectroscopy (XPS) shifts to higher binding energies with increasing Fe content (Supplementary Figure 20), and again by the positive shift in potential of the $\mathrm{Ni}^{2+13+}$ redox features upon $\mathrm{Fe}$ substitution (Fig. 4a). Fitting parameters for Mössbauer spectroscopy can be found in Supplementary Tables 4 and 5. Additional discussion of oxygen stoichiometry and LSNF oxidation states can be found in Supplementary Note 1.

To further understand the electronic structure evolution across the LSNF series and its implications for the OER activity, as well as confirm the results of the Mössbauer spectroscopy and iodometric titrations, we model the bulk phase of LSNF and a simplified $\mathrm{Sr}_{2} \mathrm{Ni}_{1-x} \mathrm{Fe}_{x} \mathrm{O}_{4}$ (SNF) series by DFT. While the SNF system was not investigated experimentally, it was modeled to confirm that the same trends in electronic structure evolution that occur in LSNF also take place in a sample with a different A-site composition. Additionally, modeling the SNF series also eliminates a possible source of variation between the atomic arrangements of A-site elements in the modeled LSNF system vs the arrangements in the synthesized samples and verifies our results on a simplified catalyst system.

A series of LSNF compositions are modeled by $2 \times 2 \times 1$ primitive unit cells, allowing for unit compositions of $\mathrm{La}_{0.5} \mathrm{Sr}_{1.5^{-}}$ $\mathrm{NiO}_{4}$ (LSN), $\mathrm{La}_{0.5} \mathrm{Sr}_{1.5} \mathrm{Ni}_{0.75} \mathrm{Fe}_{0.25} \mathrm{O}_{4}$ (LSNF25), LSNF50, LSNF75, and LSF. The SNF series was modeled using the same $\mathrm{Ni}$ and $\mathrm{Fe}$ ratios, and details regarding cell formation and magnetic investigation are given in the Methods and Supplementary Note 2. Figure $5 \mathrm{a}, \mathrm{b}$ shows the (001) atomic layers of the most stable LSNF structures based on our screening. First, we look at
LSN (Fig. 4a) and we find a uniform, proportional distribution of $\mathrm{La} / \mathrm{Sr}^{42}$. Using this $\mathrm{La} / \mathrm{Sr}$ distribution we determine the minimum energy Ni/Fe ordering which results in two key features governing the Fe arrangement in LSNF (Fig. 5b). First, each of the two $B\left(B^{\prime}\right)$ $\mathrm{O}_{2}$ layers has an equal number of $\mathrm{Fe}$ cations in order to prevent an unbalanced charge distribution between them. Second, the $\mathrm{Fe}$ cations in each $B\left(B^{\prime}\right) \mathrm{O}_{2}$ plane are distributed such that the number of $\mathrm{Fe}-\mathrm{O}-\mathrm{Ni}$ bridges is maximized ${ }^{2}$. This arrangement mitigates the effects of the induced $\mathrm{O} 2 p$ electron hole at $\mathrm{Ni}-\mathrm{O}-\mathrm{Ni}$ bridges due to more effective electron donation by $\mathrm{Fe}$ at $\mathrm{Fe}-\mathrm{O}-\mathrm{Ni}$ bridges, which increases stability ${ }^{18}$. Compared with $\mathrm{Fe}-\mathrm{O}-\mathrm{Fe}$ bridges, the $\mathrm{Fe}-\mathrm{O}-\mathrm{Ni}$ bridges induce shorter $\mathrm{Fe}-\mathrm{O}$ bond lengths and indicate higher $\mathrm{Fe}$ oxidation states, a trend that also occurs in the simplified SNF system. This observation agrees with the experimentally observed predominance of $\mathrm{Fe}^{4+}$ over $\mathrm{Fe}^{3+}$ at low Fe substitution as well as the increase in unit cell parameters as Fe content increases (Fig. 1d, Supplementary Table 1).

The computed projected density of states (PDOS) of the $\mathrm{Fe}-\mathrm{O}-\mathrm{Ni}$ bridges in both LSNF and SNF confirm that the Ni cations are in the low-spin state with fully occupied $t_{2 g}^{\downarrow}$ states (Supplementary Figures 21-23) while the Fe cations are in the high-spin state with mostly unoccupied $t_{2 g}^{\downarrow}$ states for all LSNF and $\mathrm{SNF}^{43}$. These spin states lead to $e_{g}$ bands positioned around the Fermi level $\left(E_{\mathrm{F}}^{0}\right)$, thus becoming the most relevant for $\mathrm{Fe}-\mathrm{O}-\mathrm{Ni}$ interactions of interest and the focus of our study. Inspection of the $\mathrm{Fe}-\mathrm{O}-\mathrm{Ni}$ bridges reveals significant overlap of $\mathrm{O} 2 p, \mathrm{Ni} e_{g}^{\uparrow}$ and Fe $e_{g}^{\uparrow}$ bands for all compositions in the LSNF series (Fig. $5 \mathrm{c}$ ), in agreement with our predictions. The same overlap is observed in the SNF series with only a small downward shift in $E_{\mathrm{F}}$ due to increased oxidation of the B-site elements to differentiate the two (Supplementary Figure 23). This overlap leads to two important observations. First, the unoccupied $\mathrm{O} 2 p^{\dagger}$ states indicate oxygen electron holes with finite PDOS across $E_{\mathrm{F}}^{0}$, thus bridging charge transfer between neighboring cations ${ }^{32,43}$. Second, the similar energies of the $\mathrm{Ni}$ and $\mathrm{Fe} e_{g}^{\uparrow}$ states (denoted Band I and Band II in the following) open up the possibility of electron exchange through oxygen. These two factors govern the evolution of the PDOS from LSN to LSF and from SN to SF. On the one hand, the substitution of $\mathrm{Ni}$ by less electronegative $\mathrm{Fe}$ stabilizes $\mathrm{O} 2 p$ electrons and increases the $\mathrm{Ni}-\mathrm{O}$ distances, shifting the $\mathrm{O} 2 p$ band center downwards relative to $E_{\mathrm{F}}$ (Fig. $5 \mathrm{~d}$, Supplementary Figure 23) and decreasing the bandwidth ${ }^{43}$ which reduces electron hole concentration and charge transfer ability ${ }^{44}$. This condition is consistent with the experimentally observed increase in oxygen hyperstoichiometry going from LSN to LSF (Table 1, Supplementary Table 3). On the other hand, the partially filled Band II $(\mathrm{Fe})$ significantly hybridizes with both $\mathrm{O} 2 p$ and Band I (Ni), driving the latter towards $E_{\mathrm{F}}^{0}$. Both Bands I and II make significant contributions to the occupied (valence) and 
a

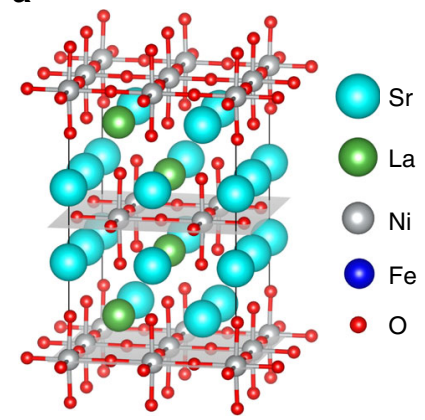

d

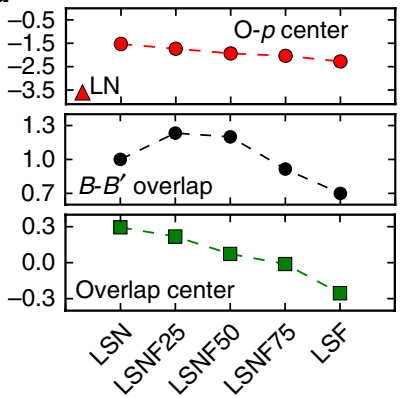

b
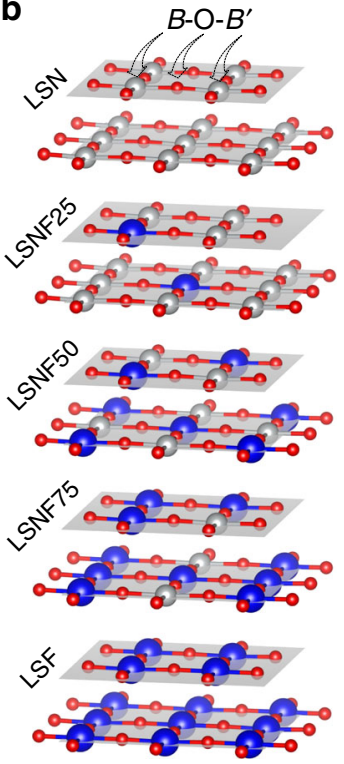

C

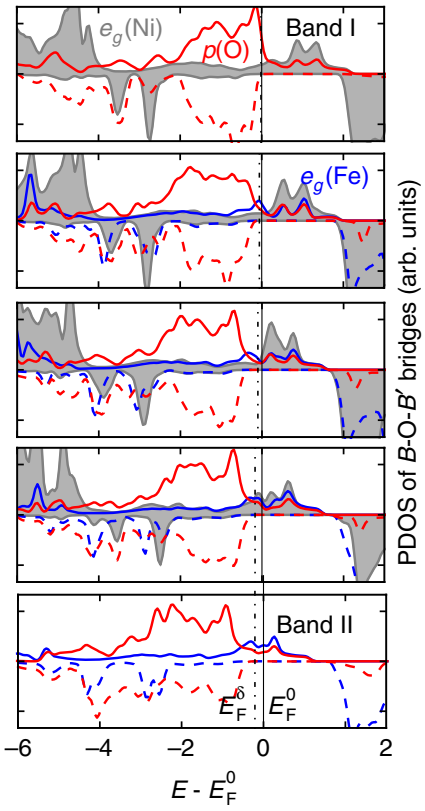

Fig. 5 Density functional theory modeling of atomic and electronic structures of bulk LSNF in ferromagnetic configuration. a The ground state $2 \times 2 \times 1$ cell of $\mathrm{La}_{0.5} \mathrm{Sr}_{1.5} \mathrm{NiO}_{4}$, with uniformly distributed $\mathrm{La}$ in each [001] $A \mathrm{O}$ layer. $\mathbf{b}$ Representations of the two $B\left(B^{\prime}\right) \mathrm{O}_{2}$ layers for each ground state $\mathrm{La}_{0.5} \mathrm{Sr}_{1.5} \mathrm{Ni}_{1-x} \mathrm{Fe}_{x} \mathrm{O}_{4}$, with $x$ at $0,0.25,0.5,0.75$, and 1 ; for each $x$, the ground state Fe arrangement is characterized by equal numbers of $\mathrm{Fe}$ in the two $B\left(B^{\prime}\right)$ $\mathrm{O}_{2}$ layers, with the $\mathrm{Fe}$ in each layer arranged to maximize the number of Fe-O-Ni bridges. $\mathbf{c}$ The corresponding spin polarized PDOS of $e_{g}$ (Ni: gray shaded area and Fe: blue line) and $2 p$ (O: red line) with respect to Fermi level $\left(E_{\mathrm{F}}^{O}\right)$ for the $B-\mathrm{O}-B^{\prime}$ bridges; the PDOS are the average of existing $B-O-B^{\prime}$ bridges; the adapted Fermi level $\left(E_{\mathrm{F}}^{\delta}\right)$ to oxygen hyperstoichiometry is estimated via the rigid band model, with $E_{\mathrm{F}}^{\delta}=E_{\mathrm{F}}^{0}-2 e^{-} \delta / D O S\left(E_{\mathrm{F}}^{0}\right)(E q .(1))$, where $\mathrm{DOS}\left(E_{\mathrm{F}}^{0}\right)$ is the total density of states at $E_{\mathrm{F}}^{0}$ per formula unit of LSNF. $\mathbf{d}$ Top: Computed values of the O-p band center (top panel), with $\mathrm{La}_{2} \mathrm{NiO}_{4}$ calculated as reference. Middle: The magnitude of band overlap, determined by the integration of maximum PDOS between $e_{g}(B)$ and $e_{g}\left(B^{\prime}\right)$ from -2 to $2 \mathrm{eV}$, normalized to $e_{g}(\mathrm{Ni})$ in LSN. Bottom: The corresponding overlap center (centroid) of maximum PDOS between $e_{g}(B)$ and $e_{g}\left(B^{\prime}\right)$. Additional details can be found in

Supplementary Note 2

unoccupied (conduction) states, respectively, and this dramatically increases the bandwidth of the triple band overlap going from LSN to LSNF50 and from SN to SNF50, with its center approaching $E_{\mathrm{F}}^{0}$. As the $e_{g}$ states are relevant for surface chemisorption, the increasing bandwidth around $E_{\mathrm{F}}^{0}$ would decrease the energetic cost to accept/donate electrons ${ }^{28}$ at the adsorbate-catalyst interface, and therefore should increase the rate of reaction according the Gerischer-Marcus model of charge transfer ${ }^{45}$. The increased Fe concentrations in LSNF75 and SNF75, however, drive Band I (Ni) into the similar distribution of Band II (Fe) and this reduces the bandwidth (Fig. 5d). This suggests that the optimal OER activity will occur for a composition between LSNF25 and LSNF50, consistent with experimental observations. Although these calculations are performed for the bulk structure of LSNF, the surface electronic structure is expected to be strongly correlated to that of bulk, similar to $\mathrm{ABO}_{3}$ perovskites as was demonstrated in previous work ${ }^{46}$, thus preserving the key feature of $\mathrm{Ni}-\mathrm{O}-\mathrm{Fe}$ hybridization and its evolution across LSNF and SNF compositions.

\section{Discussion}

The computed band structure of LSNF is similar to that reported for other highly active OER catalysts, especially those compositions with mixed transition metal sites such as $\mathrm{Ni}-\mathrm{Fe}$ layered double hydroxide catalysts ${ }^{2}$. Conesa calculated the DOS of one such polymorph, $\mathrm{FeNi}_{7} \mathrm{O}_{8}(\mathrm{OH})_{8}$ in the $2 \mathrm{H}_{\mathrm{C}}$ structure with $\mathrm{Fe}$ in $\mathrm{O}_{4}(\mathrm{OH})_{2}$ coordination, and their result is strikingly similar to that of LSNF in that $\mathrm{Ni}$ and $\mathrm{Fe} 3 d$ bands are strongly hybridized just above $E_{\mathrm{F}}$. They concluded that $\mathrm{Fe}^{4+}$ is stabilized by induced charge transfer between $\mathrm{Ni}$ sites, which is also seen in $\mathrm{Ni}-\mathrm{Fe}$ oxyhydroxides $^{6}$, and this explanation agrees with our observation of $\mathrm{Fe}$ in the $4+$ oxidation state in LSNF (Table 1). The shifting of the $\mathrm{Ni}^{2+13+}$ redox couple upon Fe substitution that we observe (Fig. 4) has previously been reported in $\mathrm{NiOOH}$ upon incorporation of $\mathrm{Fe}$ and is further evidence of this partial charge transfer between $\mathrm{Fe}$ and/or $\mathrm{Ni}^{4,5,47}$. A change in covalency by the introduction of $\mathrm{FeO}_{6}$ units into LSN must have an inductive effect on $\mathrm{Ni}$ through next nearest neighbor interactions via $\mathrm{Fe}-\mathrm{O}-\mathrm{Ni}$ bridges $^{48}$, which is consistent with the observation that our activity is maximized for the composition having the highest probability of $\mathrm{Fe}-\mathrm{O}-\mathrm{Ni}$ bridging interactions, LSNF30.

The band structure of LSNF also resembles the computed band structures of $\mathrm{LaCo}_{1-x} \mathrm{Fe}_{x} \mathrm{O}_{3}$ (ref. ${ }^{49}$ ), $\mathrm{Sr}_{2-x} \mathrm{La}_{x} \mathrm{MO}_{4 \pm \delta}$ (ref. ${ }^{50}$ ), and $\mathrm{Ba}_{0.5} \mathrm{Sr}_{0.5} \mathrm{Co}_{0.75} \mathrm{Fe}_{0.25} \mathrm{O}_{3 \pm \delta}(\mathrm{BSCF})^{51}$. Merkle calculated the band diagram for BSCF and found a similar electronic configuration as in LSNF, and Schmidt and co-workers saw that the catalytic activity of $\mathrm{Ba}_{0.5} \mathrm{Sr}_{0.5} \mathrm{Co}_{0.8} \mathrm{Fe}_{0.2} \mathrm{O}_{3 \pm \delta}$ was much higher than that of $\mathrm{Ba}_{0.5} \mathrm{Sr}_{0.5} \mathrm{CoO}_{3 \pm \delta}\left(\right.$ ref. $\left.^{34}\right)$. Thus it is possible that the high activity of BSCF, $\mathrm{SrNb}_{0.1} \mathrm{Co}_{0.7} \mathrm{Fe}_{0.2} \mathrm{O}_{3-\delta}{ }_{34,52}$ as well as others with similar mixed transition metal sites may be rationalized not just by the covalent bonding, but also by triplyoverlapping $\mathrm{Co} / \mathrm{Ni}$ and $\mathrm{Fe} 3 d$ states with $\mathrm{O} 2 p$ near $E_{\mathrm{F}}$ similar to the LSNF series, which has largely been overlooked up to now. Furthermore, the similarities between the band structures of LSNF materials and these other active catalysts of varying structures, some of them amorphous, reinforces how the 
principle of cross-gap hybridization may apply to many different metal oxide catalysts and applies to the LSNF series even in the event of surface restructuring.

As we have discussed in our previous work, the OER can proceed by the adsorbate exchange mechanism (AEM) or the LOM mechanism ${ }^{14,18}$. In the AEM, chemisorbed intermediates undergo a series of electrochemical oxidations as the transition metal active site undergoes oxidation and reduction, and these redox reactions are the most energetically intensive and thus rate limiting steps ${ }^{14}$. The LOM OER mechanism, on the other hand, does not require significant redox switching of transition metal sites but instead requires the participation of lattice oxygen in the OER. Ligand holes that arise when transition metal $3 d$ bands are highly covalent with $\mathrm{O} 2 p$ bands and exist around $E_{\mathrm{F}}^{0}$ activate lattice oxygen that combines with chemisorbed $\mathrm{OH}$ to produce $\mathrm{O}_{2}{ }^{-}$. In previous studies we found that the DFT-computed $\mathrm{O}_{\mathrm{vac}}$ formation energy in bulk $A B \mathrm{O}_{3}$ perovskites (donated as $\Delta E_{V}$ ) served as an effective indicator of OER mechanism ${ }^{18}$. Highly covalent perovskites favor $\mathrm{O}_{\mathrm{vac}}$ formation that results from an overall high-energy lying $\mathrm{O} 2 p$ band relative to $E_{\mathrm{F}}^{0}$ and the appearance of electron holes that facilitate reversible lattice oxygen participation under OER conditions. Employing $\Delta E_{V_{0}}$, we showed that the mechanism for oxygen evolution switches from the AEM to the LOM with decreasing $\Delta E_{V_{O}}$ for the $\mathrm{La}_{x} \mathrm{Sr}_{1}$ ${ }_{-x} \mathrm{CoO}_{3-\delta}$ series when $x>0.4$ (ref. ${ }^{14}$ ). The decrease in oxygen vacancy formation energy in these materials occurred in concert with an increase in oxygen diffusion rates and OER activity ${ }^{14}$. This proposed mechanistic switch was experimentally confirmed by a recent report from the Shao Horn group who used isotopic labeling of lattice oxygen to observe a transition from the AEM on $\mathrm{LaCoO}_{3}$ to the LOM on $\mathrm{La}_{0.5} \mathrm{Sr}_{0.5} \mathrm{CoO}_{3-\delta}$ and $\mathrm{SrCoO}_{3-\delta}{ }^{17}$.

The same type of band overlap and resulting covalency that is a requirement of the LOM mechanism and that occurs in the previously reported materials discussed above also occurs in LSNF. The hybridization of $e_{g}(\mathrm{Ni})$ and $e_{g}(\mathrm{Fe})$ bands with the $p(\mathrm{O})$ band across $E_{\mathrm{F}}^{0}$ results in increased oxygen electron holes, and DFT computations reveal that $\Delta E_{V_{0}}$ in LSN, LSNF25, and LSNF50 at Ni-O-Fe bridges is more negative than in $\mathrm{LaNiO}_{3}$ and $\mathrm{La}_{0.5} \mathrm{Sr}_{0.5} \mathrm{CoO}_{3-\delta}{ }^{18}$ while $\Delta E_{V_{0}}$ in LSNF75 and LSF is larger (Supplementary Table 6). Thus $\Delta E_{V_{0}}$, a proven indicator of the LOM mechanism, works in conjunction with the experimentally measured increased oxygen diffusion rates from LSN to LSNF45 (Supplementary Figure 17, Supplementary Table 3), to suggest that the exchange of surface lattice $O$ plays a key role in OER and that the highly active LSNF materials utilize a LOM-type mechanism. The catalytic effect from the LOM mechanism is further enhanced by the substitution of Fe that causes broadening of $e_{g}$ bandwidth through $\mathrm{Ni}-\mathrm{O}-\mathrm{Fe}$ cross-gap hybridization. Altogether this demonstrates how the LOM applies to a new series of materials and solidifies the importance of both increased covalency that results in oxygen electron holes, as well as the cross-gap hybridization that causes broadening of the overall bandwidth near $E_{\mathrm{F}}$ in the design and optimization of oxide catalysts.

We have precisely synthesized a series of RP catalysts having highly oxidized and covalent $\mathrm{Ni} 3 d-\mathrm{O} 2 p-\mathrm{Fe} 3 d$ bonds that give rise to exceptional OER activity. Sr substitution into the perovskite $\mathrm{LaNiO}_{3}$ has previously been proposed as an avenue to increase the oxidation state if $\mathrm{Ni}$ and $\mathrm{Ni}-\mathrm{O}$ covalency but has not been fully realized. In this work we were able to avoid inactive secondary phases resulting from poor solubility of $\mathrm{Sr}$ in the perovskite phase through utilization of the RP crystal structure. Additionally, by using $\mathrm{La}_{0.5} \mathrm{Sr}_{1.5} \mathrm{NiO}_{4 \pm \delta}$ as the host lattice we achieved complete substitution of $\mathrm{Fe}$ for $\mathrm{Ni}$ across the entire compositional range. The crystalline RP structure and the high degree of phase purity enabled precise study of the impact of $\mathrm{Fe}$ substitution on the chemical and electronic properties of the LSNF series, something that has not been possible up to this point with other, amorphous materials. Iodometric titrations coupled with Mössbauer spectroscopy indicate that the average $\mathrm{Ni}$ oxidation state in the LSNF series increases from +3.46 to +3.95 with increasing $\mathrm{Fe}$ substitution while the $\mathrm{Ni}^{2+/ 3+}$ redox peaks also shift to more positive potentials, consistent with Ni developing a more oxidized character. The influence of Fe substitution extends beyond increasing the oxidative strength of $\mathrm{Ni}$, however, as the electrocatalytic activity increases by over an order of magnitude from LSN to LSNF30 despite possessing statistically equivalent $\mathrm{Ni}$ oxidation states. DFT calculations reveal that $\mathrm{Fe}$ substitution results in cross-gap hybridization where the Fe $3 d e_{g}$ band is hybridized with both the Ni $3 d e_{g}$ and the top of the $\mathrm{O} 2 p$ density of states across the Fermi level. The increased covalency of the Ni-O bonds as well as facile charge transfer through $\mathrm{Fe}-\mathrm{O}-\mathrm{Ni}$ bridges due to incorporation of $\mathrm{Fe}$ explains the enhanced catalytic activity going from LSN to LSNF30. Furthermore, the increased covalency demonstrated via calculated partial density of states for LSNF and a simplified SNF that is a requirement for the OER to take place via a LOM mechanism resembles the band structure of other highly active OER catalysts with varying crystal or amorphous structures for which this mechanism has already been verified. Decreased oxygen vacancy formation energies and increased rates of oxygen diffusion, descriptors already accepted in the literature as indications of the LOM, are seen on LSNF and further support the hypothesis that the OER proceeds via a LOM mechanism on LSNF. This methodology of selective A- and B-site substitution to promote crossgap hybridization in RP oxides reveals important fundamental aspects related to their structure and the exceptional electrocatalytic activities of these materials as well as other metal oxide catalysts.

\section{Methods}

General. All chemicals were used as they were received from manufacturers. Lanthanum(III) nitrate hexahydrate (99.995\%), strontium(II) nitrate hexahydrate (99\%), nickel(II) nitrate hexahydrate (99\%), iron(III) nitrate non-ahydrate (99.99\%), tetramethylammonium hydroxide pentahydrate (TMAOH, 99\%), diethylene glycol (DEG, 99.99\%), citric acid monohydrate, 2-propanol, ethylenediaminetetraacetic acid, and potassium hydroxide $(\mathrm{KOH})$ were purchased from Fisher Scientific. Absolute 200 proof ethanol was obtained from Aaper Alcohol. 5 wt \% Nafion solution in lower alcohols and $\mathrm{IrO}_{2}$ powder were obtained from SigmaAldrich. Millipore high-purity water (DI water, $18 \mathrm{M} \Omega$ ) was used in all experiments and synthesis and research grade, $99.999 \%$ purity oxygen and argon gases were purchased from Praxair. Vulcan XC72 carbon (VC) was purchased from Cabot Corporation and ball-milled prior to use.

Catalyst synthesis. $\mathrm{La}_{0.5} \mathrm{Sr}_{1.5} \mathrm{Ni}_{1-x} \mathrm{Fe}_{x} \mathrm{O}_{4 \pm \delta}$ (LSNF, $x=0$ to 1 ) samples were synthesized using a modified Pechini method ${ }^{29}$ followed by crystallization and annealing. A- and B-site nitrate salts, in stoichiometric ratios, were dissolved in water to create a solution in which the total concentration of metal salts was $0.1 \mathrm{M}$. Citric acid and EDTA were added, each at a concentration of $0.1 \mathrm{M}$, and then $1 \mathrm{M}$ TMAOH was added dropwise until the $\mathrm{pH}$ had reached 7.5 in order to deprotonate and dissolve the EDTA. DEG was then injected to reach a concentration of $0.067 \mathrm{M}$ and the solution was heated to $85^{\circ} \mathrm{C}$ while stirring. The EDTA and citric acid were both added to ensure complete chelation of the metal cations, preventing agglomerations or particle formations that may lead to catalyst inhomogeneity. DEG and heat were added to the solution to drive a dehydration reaction between the polyhydroxyl alcohol and the carboxylic acid groups of the chelates to form a polyester gel. Once all the water had been evaporated the gel was combusted on a hot plate at $350^{\circ} \mathrm{C}$ to form mixed metal oxide precursor particles. This step was performed on a hot place and not in a sealed tube furnace to avoid possible explosions from rapid evolution of gasses upon combustion. Finally, precursor particles were crystallized at $950^{\circ} \mathrm{C}$ (heated at $20^{\circ} \mathrm{C} \mathrm{min}-1$ ) for $5 \mathrm{~h}$ then cooled to $400^{\circ} \mathrm{C}$ and left to anneal for $6 \mathrm{~h}$ in a tube furnace. The entire crystallization and annealing routine was done under pure $\mathrm{O}_{2}$ flowing at $200 \mathrm{~mL} \mathrm{~min}^{-1}$. Catalysts were recovered and immediately stored under Ar gas to prevent catalyst surface amorphization. Total catalyst yields per synthesis ranged from 500 to $750 \mathrm{mg}$. More details regarding the synthesis can be found in Kakihana et al. ${ }^{31}$

$\mathrm{SrCoO}_{2.7}$ and $\mathrm{LaNiO}_{3}$ were synthesized via a coprecipitation method previously reported elsewhere ${ }^{13,46}$ in which $\mathrm{A}$ and $\mathrm{B}$-site nitrate salts in a 1:1 ratio were 
dissolved in a $1 \mathrm{wt} \%$ solution of TMAOH containing an equimolar amount of TPAB to the total moles of metal cations in order to form mixed metal hydroxide precursor particles. These solutions were flash-frozen on a rotating metal drum that had been cooled to cryogenic temperatures and was collected before lyophilization to remove water. The precursor particles were then calcined at $700{ }^{\circ} \mathrm{C}\left(\mathrm{LaNiO}_{3}\right)$ or $950^{\circ} \mathrm{C}\left(\mathrm{SrCoO}_{2.7}\right)$ to form the perovskite phase.

Electrochemical characterization. To make catalyst inks $2 \mathrm{mg}$ of catalyst powder were added to $2 \mathrm{~mL}$ of $\mathrm{NaOH}$ neutralized $0.05 \mathrm{wt} \%$ Nafion solution ${ }^{47}$ and bath sonicated for at least $1 \mathrm{~h}$. Ten microliters of catalyst ink was drop cast onto $5 \mathrm{~mm}$ glassy carbon electrodes (GCE) from Pine Instruments and dried in air overnight. All GCEs were polished before drop casting via sonication in a solution of equal parts water and ethanol followed by polishing using $0.05 \mu \mathrm{m}$ alumina powder after which they were again sonicated in a fresh solution of water and ethanol and dried in ambient air. This method was used to clean all GCEs prior to drop casting, after which a composite catalyst loading of $51 \mu \mathrm{g}_{\text {total }} \mathrm{cm}^{-2}$ geo, yielding $15.3 \mu \mathrm{g}_{\text {oxide }} \mathrm{cm}$

${ }^{-2}$ geo was achieved for catalysis and intercalation tests.

CH Instruments CHI832a or Metrohm Autolab PGSTAT302N potentiostats were used to carry out all electrochemical testing. Potentiostats were equipped with high-speed rotators from Pine Instruments. Experiments were performed at room temperature in $0.1 \mathrm{M} \mathrm{KOH}$ (measured $\mathrm{pH} \approx 12.8$ ). Electrolyte resistance was measured using current interrupt and positive feedback methods $(46 \Omega)$ and iR compensation was applied to all electrochemical measurements after testing unless otherwise noted. A 3 electrode cell was used for all experiments. The reference electrode was a $\mathrm{CH}$ Instruments $\mathrm{Hg} / \mathrm{HgO}(1 \mathrm{M} \mathrm{KOH})$ reference electrode, a $\mathrm{Au}$ wire served as the counter electrode, and GCEs drop cast with catalyst ink and dried as described above were used as the working electrode. All potentials were measured vs $\mathrm{Hg} / \mathrm{HgO}$ but were reported vs the reversible hydrogen electrode (RHE), which was determined experimentally to be $+0.8976 \mathrm{~V}$ vs. $\mathrm{Hg} / \mathrm{HgO}(1 \mathrm{M}$ $\mathrm{KOH})$. Supplementary Figure 8 contains the RHE calibration data.

All testing for OER activities was performed on newly dropcast electrodes which had not undergone previous testing, dropcast with $30 \mathrm{wt} \%$ catalyst on VC $\left(15.3 \mu \mathrm{g}_{\text {oxide }} \mathrm{cm}^{-2}{ }_{\text {geo }}\right)$ or unsupported catalyst. CV scans were performed from 1 to $2 \mathrm{~V}$ vs RHE at a scan rate of $10 \mathrm{mV} \mathrm{s}^{-1}$ while rotating at $1600 \mathrm{rpm}$ in $\mathrm{O}_{2}$-saturated $0.1 \mathrm{M} \mathrm{KOH}$. The anodic and cathodic scans were averaged and iR corrected, and the current at $1.63 \mathrm{~V}$ vs RHE-iR was used for comparison of OER activities. Scatter in the data at high current densities is due to oxygen bubble formation and desorption on the electrode surface. Data presented in this report are the average of at least three tests on fresh electrodes. OER testing using $\mathrm{Ni}$ foam supports were performed under the same electrolyte conditions but dropcast at $1 \mathrm{mg} \mathrm{cm}^{-2}$ and held stationary.

All CVs were taken on fresh electrodes of $30 \mathrm{wt} \%$ oxide on VC. All catalysts were first conditioned by performing 20 cycles from 1.26 to $1.55 \mathrm{~V}$ vs RHE at 100 $\mathrm{mV} \mathrm{s}^{-1}$. Immediately following, three cycles at $100,50,25,10$, and $5 \mathrm{mV} \mathrm{s}^{-1}$ were collected. Unless otherwise stated, all cycles shown are the third cycle at a given scan rate. For samples containing more than $50 \%$ Fe substitution, it was necessary to perform four cycles at each scan rate. Additionally, LSNF85 had to be cycled to $1.575 \mathrm{~V}$ before any oxidative features were observed.

For comparison of charge passed for all oxidative waves, the last cycle at $10 \mathrm{mV}$ $\mathrm{s}^{-1}$ was used to compute specific current density. The baseline of each CV was fit and subtracted from the specific current density. The background subtracted CVs (Supplementary Figure 16) were then integrated to find the total charge transferred.

All RRDE tests were performed in argon-saturated, $0.1 \mathrm{M} \mathrm{KOH}$ on fresh $30 \mathrm{wt} \%$ oxide films. LSNF30 was cycled at $10 \mathrm{mV} \mathrm{s}^{-1}$ on the disk while the Pt ring was held at $-0.4 \mathrm{~V}$ vs. RHE. One-fourth the normal geometric loading of catalyst was used $\left(3.8 \mu \mathrm{g}_{\text {oxide }} \mathrm{cm}^{-2}\right.$ geo $)$ to limit the amount of oxygen generated a minimize bubble formation which reduces collection efficiency. Additional information regarding the RRDE calibration data can be found in Supplementary Figure 10.

All oxygen diffusion tests were performed in argon-saturated, $1 \mathrm{M} \mathrm{KOH}$ on fresh $85 \mathrm{wt} \%$ oxide films. Each LSNF composition was cycled at $20 \mathrm{mV} \mathrm{s}^{-1}$ until the oxidative peak potential did not change upon further cycling. Chronoamperometry was then performed at potentials $10 \mathrm{mV}$ more anodic than $E_{\mathrm{p}}$ to ensure diffusion-limited intercalation. Linear regression was performed as described elsewhere ${ }^{48,49}$ to determine the diffusion rate. Particle sizes were estimated using the surface area calculated from BET measurements and densities determined by Rietveld analysis. All values reported are the average of at least three tests.

lodometric titrations. Iodometric titrations were performed following the procedure referenced above ${ }^{13}$. In this procedure $3 \mathrm{~mL}$ of $2 \mathrm{M} \mathrm{KI}$ solution that had previously been deoxygenated were combined in a flask with $15-20 \mathrm{mg}$ of perovskite and stirred for $3 \mathrm{~min}$ under argon, after which $25 \mathrm{~mL}$ of $1 \mathrm{M} \mathrm{HCl}$ was added to dissolve the perovskite. The solution was then titrated with a solution of $\sim 26$ $\mathrm{mM}$ solution of $\mathrm{Na}_{2} \mathrm{~S}_{2} \mathrm{O}_{3}$ that had been pre-standardized with $0.1 \mathrm{~N} \mathrm{KIO}_{3}$ until a faint golden color was reached, after which a starch indicator was injected and the titration was continued until the solution was clear, marking the end point.

Catalyst preparation and support. Fresh, Ar-sealed catalysts were ball milled for 3 min using a Wig-L-Bug spectroscopic grinding mill. To support the catalysts onto
VC, the correct amounts of pre-ground catalyst and pre-ground VC were measured into the grinding mill's vial and ball milled for $3 \mathrm{~min}$.

Powder X-ray diffraction (PXRD). Catalyst structure was examined by performing X-ray diffraction with a Rigaku MiniFlex600 Diffractometer. Measurements were performed at $298 \mathrm{~K}$ in ambient conditions while the instrument operated at $40 \mathrm{kV}$ and $15 \mathrm{~mA}$ using $\mathrm{Cu} \mathrm{Ka}$ radiation (1.54 $\AA$ wavelength). For all tests, argon-sealed catalyst powder was exposed to ambient air and scanned over $10-100^{\circ} 2 \theta$ in $0.01^{\circ}$ increments with a dwell time of $0.35 \mathrm{~s}$ per step. PXRD patterns for the Rietveld refinement were taken with a Huber G670 Guinier diffractometer $\left(\mathrm{Cu} \mathrm{K} \mathrm{K}_{\alpha 1}\right.$ radiation; curved $\mathrm{Ge}(111)$ monochromator; image plate). The refinement was performed with the JANA2006 package ${ }^{50}$. As the electron diffraction patterns of all compositions revealed no deviation from the RP $n=1 \mathrm{I} / \mathrm{mmm}$ structure, the $\mathrm{La}_{2} \mathrm{NiO}_{4}$ structure ${ }^{51}$ was used as a starting model. The La/Sr occupancy factors of the A positions were refined; the $\mathrm{Fe} / \mathrm{Ni}$ occupancy factors for the $\mathrm{B}$ positions were assigned according to the results of the EDX analysis. The crystallographic data, positional and atomic displacement parameters, interatomic distances, and reliability factors are listed in Supplementary Table 1.

Surface area analysis. Catalyst surface areas were measured via nitrogen sorption analysis which was performed at a temperature of $77 \mathrm{~K}$ on a Quantachrome Instruments NOVA 2000 high-speed surface area BET analyzer. Before BET experiments were performed, all catalyst materials were ball milled for $3 \mathrm{~min}$ followed by degassing under vacuum at room temperature for at least $12 \mathrm{~h}$. Only data in the relative pressure range $(P / P 0)$ of 0.05 to 0.30 , with a minimum $R^{2}$ of 0.995 and $C$ value of 20 was used to calculate the specific surface area using the BET method.

Transmission electron microscopy. Preparation of TEM samples was performed by mixing the crystals with ethanol and crushing them in a mortar, after which drops of the suspension were deposited onto holey carbon grids. Electron diffraction patterns, TEM images, HAADF-STEM images, ABF-STEM images, and energy dispersive X-ray (EDX) spectra were collected using an aberration-corrected Titan $\mathrm{G}^{3}$ electron microscope equipped with a Super-X EDX system, operating at $200 \mathrm{kV}$ using a convergence semi-angle of $21.6 \mathrm{mrad}$

Mössbauer spectroscopy. ${ }^{57} \mathrm{Fe}$ Mössbauer spectra were collected using a constant acceleration spectrometer MS1104 (Rostov-na-Donu, RF) in transmission mode with a ${ }^{57} \mathrm{Co} / \mathrm{Rh} \gamma$-ray source. Calibration of the spectrometer was performed using standard sodium nitroprusside absorbers. All isomer shift values (IS) are referred to $\alpha$-Fe at room temperature and spectra evaluation was performed using "UnivemMS" (Rostov-na-Donu, RF) and custom least squares fitting software with Lorentzian-Gaussian line shapes. Details regarding the deconvolution of the spectra are found in the text accompanying Supplementary Figure 18.

DFT modeling. The Vienna Ab initio Simulation Package (VASP) was used to do spin polarized calculations ${ }^{52}$, using the PAW pseudopotentials and the exchangecorrelation functional of Perdew-Burke-Ernzerhof (PBE), with the effective Hubbard $U_{\text {eff }}$ of $5.3(\mathrm{Fe})$ and $6.2 \mathrm{eV}(\mathrm{Ni})$, respectively. The Ruddlesden-Popper bulk phase is modeled by fully relaxing a $2 \times 2 \times 1$ primitive unit cell, $\mathrm{La}(\mathrm{Sr})_{16} \mathrm{Ni}$ $(\mathrm{Fe})_{8} \mathrm{O}_{32}$, with a plane wave cutoff energy of $520 \mathrm{eV}$, Monkhorst-Pack $k$-point of $4 \times 4 \times 2$, forces convergence criterion of $10-4 \mathrm{eV}^{-1}$ and Gaussian smearing, where the smearing width is $0.1 \mathrm{eV}$. All models follow ferromagnetic ordering, as our calculations indicate its lower energy than those of nonmagnetic and antiferromagnetic orderings (A, C, and G type). Details regarding the determinations of effective Hubbard $U_{\text {eff, }}$ atomic, magnetic and electronic structures, and oxygen hyperstoichiometry effects are provided Supplementary Note 2.

X-ray photoelectron spectroscopy. Characterization of the chemical states was done using a Kratos AXIS Ultra DLD XPS and a monochromatic Al X-ray source $(\mathrm{Al} \alpha, 1.4866 \mathrm{eV})$, scanning in $0.1 \mathrm{eV}$ steps with a dwell time of $4 \mathrm{~s}$ per step. Charge compensation was used for all samples. Binding energies were for all spectra were calibrated against the adventitious carbon peak at $285 \mathrm{eV}$. CasaXPS was used for all data analysis and deconvolution. Details regarding the deconvolution of the Ni $3 p$ spectrum are found in the text accompanying Supplementary Figure 20.

Determination of $\mathrm{Ni}$ and Fe oxidation states. Together, the iodometric titrations and the Mössbauer spectroscopy enable the calculation of Ni's average oxidation state and the relative percentage of $\mathrm{Fe}^{3+/ 4+}$. Supplementary Figure 18 contains the deconvolution method and Mössbauer spectra.

Data availability. The authors declare that all data collected and discussed in support of the findings of this study are available within the paper and its Supplementary Information. 
Received: 7 September 2017 Accepted: 18 July 2018

Published online: 08 August 2018

\section{References}

1. Zhu, H., Zhang, P. \& Dai, S. Recent advances of lanthanum-based perovskite oxides for catalysis. ACS Catal. 5, 6370-6385 (2015).

2. Conesa, J. C. Electronic structure of the (undoped and Fe-doped) $\mathrm{NiOOH} \mathrm{O}_{2}$ evolution electrocatalyst. J. Phys. Chem. C 120, 18999-19010 (2016).

3. Corrigan, D. A. The catalysis of the oxygen evolution reaction by iron impurities in thin film nickel oxide electrodes. J. Electrochem. Soc. 134, 377-384 (1987).

4. Trotochaud, L., Young, S. L., Ranney, J. K. \& Boettcher, S. W. Nickel-iron oxyhydroxide oxygen-evolution electrocatalysts: the role of intentional and incidental iron incorporation. J. Am. Chem. Soc. 136, 6744-6753 (2014).

5. Dionigi, F. \& Strasser, P. NiFe-based (oxy)hydroxide catalysts for oxygen evolution reaction in non-acidic electrolytes. Adv. Energy Mater. 6, 1600621 (2016).

6. Chen, J. Y. C. et al. Operando analysis of NiFe and Fe oxyhydroxide electrocatalysts for water oxidation: detection of Fe4+ by Mössbauer spectroscopy. J. Am. Chem. Soc. 137, 15090-15093 (2015).

7. Görlin, M. et al. Tracking catalyst redox states and reaction dynamics in $\mathrm{Ni}-\mathrm{Fe}$ oxyhydroxide oxygen evolution reaction electrocatalysts: the role of catalyst support and electrolyte pH. J. Am. Chem. Soc. 139, 2070-2082 (2017).

8. Hunter, B. M., Gray, H. B. \& Müller, A. M. Earth-abundant heterogeneous water oxidation catalysts. Chem. Rev. 116, 14120-14136 (2016).

9. Bockris, J. O. \& Otagawa, T. Mechanism of oxygen evolution on perovskites. J. Phys. Chem. 87, 2960-2971 (1983).

10. Suntivich, J., May, K. J., Gasteiger, H. A., Goodenough, J. B. \& Shao-Horn, Y. A perovskite oxide optimized for oxygen evolution catalysis from molecular orbital principles. Science 334, 1383-1385 (2011).

11. Hardin, W. G. et al. Tuning the electrocatalytic activity of perovskites through active site variation and support interactions. Chem. Mater. 26, 3368-3376 (2014).

12. Galasso, F. S. Structure, Properties and Preparation of Perovskite-Type Compounds (Pergamon Press, Oxford, United Kingdom, 1969).

13. Yagi, S. et al. Covalency-reinforced oxygen evolution reaction catalyst. Nat. Commun. 6, 9249 (2015)

14. Mefford, J. T. et al. Water electrolysis on $\mathrm{La}_{1-x} \mathrm{Sr}_{x} \mathrm{CoO}_{3-\delta}$ perovskite electrocatalysts. Nat. Commun. 7, 11053 (2016).

15. Zhou, W., Zhao, M., Liang, F., Smith, S. C. \& Zhu, Z. High activity and durability of novel perovskite electrocatalysts for water oxidation. Mater. Horiz. 2, 495-501 (2015).

16. Man, I. C. et al. Universality in oxygen evolution electrocatalysis on oxide surfaces. ChemCatChem 3, 1159-1165 (2011).

17. Grimaud, A. et al. Activating lattice oxygen redox reactions in metal oxides to catalyse oxygen evolution. Nat. Chem. 9, 457-465 (2017).

18. Rong, X., Parolin, J. \& Kolpak, A. M. A fundamental relationship between reaction mechanism and stability in metal oxide catalysts for oxygen evolution. ACS Catal. 6, 1153-1158 (2016).

19. Takeda, Y. et al. Synthesis of $\mathrm{SrNiO}_{3}$ and related compound, $\mathrm{Sr}_{2} \mathrm{Ni}_{2} \mathrm{O}_{5}$. J. Inorg. Nucl. Chem. 34, 1599-1601 (1972).

20. Oliveira, F. S., Pimentel, P. M., Oliveira, R. M. P. B., Melo, D. M. A. \& Melo, M. A. F. Effect of lanthanum replacement by strontium in lanthanum nickelate crystals synthetized using gelatin as organic precursor. Mater. Lett. 64, 2700-2703 (2010).

21. Seki, H., Saito, T. \& Shimakawa, Y. High pressure synthesis of $\mathrm{SrFe}_{1-\mathrm{x}} \mathrm{Ni}_{\mathrm{x}} \mathrm{O}_{3}$. J. Jpn Soc. Powder Powder Metall. 63, 609-612 (2016).

22. Sharma, I. B. \& Singh, D. Solid state chemistry of Ruddlesden-Popper type complex oxides. Bull. Mater. Sci. 21, 363-374 (1998).

23. Amow, G., Davidson, I. J. \& Skinner, S. J. A comparative study of the Ruddlesden-Popper series, $\mathrm{La}_{\mathrm{n}+1} \mathrm{Ni}_{\mathrm{n}} \mathrm{O}_{3 \mathrm{n}+1}(\mathrm{n}=1,2$ and 3), for solid-oxide fuel-cell cathode applications. Solid State Ionics 177, 1205-1210 (2006).

24. Zhang, Z. \& Greenblatt, M. Synthesis, structure, and properties of $\mathrm{Ln}_{4} \mathrm{Ni}_{3} \mathrm{O}_{10-\delta}$ ( $\mathrm{Ln}=\mathrm{La}, \mathrm{Pr}$, and Nd). J. Solid State Chem. 117, 236-246 (1995).

25. Takeda, Y. et al. Crystal chemistry and physical properties of $\mathrm{La}_{2-\mathrm{x}} \mathrm{Sr}_{\mathrm{x}} \mathrm{NiO}_{4}$ $(0 \leq \mathrm{x} \leq 1.6)$. Mater. Res. Bull. 25, 293-306 (1990).

26. Benloucif, R., Nguyen, N., Greneche, J. M. \& Raveau, B. $\mathrm{La}_{2-2 x} \mathrm{Sr}_{2 \mathrm{x}} \mathrm{Ni}_{1-\mathrm{x}} \mathrm{Fe}_{\mathrm{x}}$ $\mathrm{O}_{4-(\mathrm{x} 2)+\delta}$ : magnetic and electron transport properties. J. Phys. Chem. Solids 50, 435-440 (1989).

27. Rao, C. N. R., Ganguly, P., Singh, K. K. \& Ram, R. A. M. A comparative study of the magnetic and electrical properties of perovskite oxides and the corresponding two-dimensional oxides of K2NiF4 structure. J. Solid State Chem. 72, 14-23 (1988).
28. F Howlett, J. et al. Electronic structure, reactivity and solid-state chemistry of $\mathrm{La}_{2} \mathrm{Sr}_{\mathrm{x}} \mathrm{Ni}_{1-\mathrm{y}} \mathrm{Fe}_{\mathrm{y}} \mathrm{O}_{4+\delta}$. Faraday Discuss. 105, 337-354 (1996).

29. Gilev, A. R., Kiselev, E. A. \& Cherepanov, V. A. Homogeneity range, oxygen nonstoichiometry, thermal expansion and transport properties of $\mathrm{La}_{2-\mathrm{x}} \mathrm{Sr}_{\mathrm{x}}$ $\mathrm{Ni}_{1-\mathrm{y}} \mathrm{Fe}_{\mathrm{y}} \mathrm{O}_{4+\delta}$. RSC Adv. 6, 72905-72917 (2016).

30. Cohen, R. E. Origin of ferroelectricity in perovskite oxides. Nature 358, 136-138 (1992).

31. Kakihana, M. \& Yoshimura, M. Synthesis and characteristics of complex multicomponent oxides prepared by polymer complex method. Bull. Chem. Soc. Jpn. 72, 1427-1443 (1999).

32. Erat, S. et al. Entanglement of charge transfer, hole doping, exchange interaction, and octahedron tilting angle and their influence on the conductivity of $\mathrm{La}_{1-\mathrm{x}} \mathrm{Sr}_{\mathrm{x}} \mathrm{Fe}_{0.75} \mathrm{Ni}_{0.25} \mathrm{O}_{3-\delta}$ : a combination of $\mathrm{x}$-ray spectroscopy and diffraction. J. Appl. Phys. 108, 124906 (2010).

33. Mefford, J. T., Hardin, W. G., Dai, S., Johnston, K. P. \& Stevenson, K. J. Anion charge storage through oxygen intercalation in $\mathrm{LaMnO} 3$ perovskite pseudocapacitor electrodes. Nat. Mater. 13, 726-732 (2014).

34. Fabbri, E. et al. Dynamic surface self-reconstruction is the key of highly active perovskite nano-electrocatalysts for water splitting. Nat. Mater. 16, 925-931 (2017).

35. Louie, M. W. \& Bell, A. T. An investigation of thin-film Ni-Fe oxide catalysts for the electrochemical evolution of oxygen. J. Am. Chem. Soc. 135, 12329-12337 (2013).

36. Forslund, R. P. et al. Nanostructured $\mathrm{LaNiO}_{3}$ perovskite electrocatalyst for enhanced urea oxidation. ACS Catal. 6, 5044-5051 (2016).

37. Bhavaraju, S., DiCarlo, J. F., Scarfe, D. P., Jacobson, A. J. \& Buttrey, D. J. Electrochemical oxygen intercalation in $\mathrm{La}_{2} \mathrm{NiO}_{4+\delta}$ crystals. Solid State Ionics 86, 825-831 (1996).

38. Conway, B. E. Electrochemical Supercapacitors (Springer, New York, NY, United States of America, 1999).

39. Sreedhar, K. \& Honig, J. M. Low-temperature electron transport properties of $\mathrm{La}_{2-\mathrm{x}} \mathrm{Sr}_{\mathrm{x}} \mathrm{NiO}_{4}$ with $0.5 \leq \mathrm{x} \leq 1.3$. J. Solid State Chem. 111, 147-150 (1994).

40. Anisimov, V. I., Bukhvalov, D. \& Rice, T. M. Electronic structure of possible nickelate analogs to the cuprates. Phys. Rev. B 59, 7901-7906 (1999).

41. Falcón, H., Carbonio, R. E. \& Fierro, J. L. G. Correlation of oxidation states in $\mathrm{LaFe}_{\mathrm{x}} \mathrm{Ni}_{1-\mathrm{x}} \mathrm{O}_{3+\delta}$ oxides with catalytic activity for $\mathrm{H}_{2} \mathrm{O}_{2}$ decomposition. J. Catal. 203, 264-272 (2001).

42. Ritzmann, A. M., Muñoz-García, A. B., Pavone, M., Keith, J. A. \& Carter, E. A. $\mathrm{Ab}$ initio DFT $+\mathrm{U}$ analysis of oxygen vacancy formation and migration in $\mathrm{La}_{1}$ ${ }_{\mathrm{x}} \mathrm{Sr}_{\mathrm{x}} \mathrm{FeO}_{3-\delta}(\mathrm{x}=0,0.25,0.50)$. Chem. Mater. 25, 3011-3019 (2013).

43. Mogni, L. et al. Synthesis, crystal chemistry and physical properties of the Ruddlesden-Popper phases $\mathrm{Sr}_{3} \mathrm{Fe}_{2-\mathrm{x}} \mathrm{Ni}_{\mathrm{x}} \mathrm{O}_{7-\delta}(0 \leq \mathrm{x} \leq 1.0)$. J. Solid State Chem. 178, 1559-1568 (2005).

44. Torrance, J. B., Lacorre, P., Nazzal, A. I., Ansaldo, E. J. \& Niedermayer, C. Systematic study of insulator-metal transitions in perovskites $\mathrm{RNiO} 3(\mathrm{R}=\mathrm{Pr}$, $\mathrm{Nd}, \mathrm{Sm}, \mathrm{Eu})$ due to closing of charge-transfer gap. Phys. Rev. B 45, 8209-8212 (1992).

45. Bard, A. J. \& Faulkner, L. R. Electrochemical Methods: Fundamentals and Applications (Wiley, New York, NY, United States of America, 2000).

46. Akhade, S. A. \& Kitchin, J. R. Effects of strain, $d$-band filling, and oxidation state on the surface electronic structure and reactivity of $3 d$ perovskite surfaces. J. Chem. Phys. 137, 084703 (2012).

47. Corrigan, D. A., Conell, R. S., Fierro, C. A. \& Scherson, D. A. In-situ Moessbauer study of redox processes in a composite hydroxide of iron and nickel. J. Phys. Chem. 91, 5009-5011 (1987).

48. Goodenough, J. B. Magnetism and The Chemical Bond (John Wiley and Sons, WIley, New York, NY, United States, 1963).

49. Duan, Y. et al. Tailoring the $\mathrm{Co} 3 \mathrm{~d}-\mathrm{O} 2 \mathrm{p}$ covalency in $\mathrm{LaCoO}_{3}$ by Fe substitution to promote oxygen evolution reaction. Chem. Mater. 29, 10534-10541 (2017).

50. Lee, Y.-L. et al. Kinetics of oxygen surface exchange on epitaxial Ruddlesden-Popper phases and correlations to first-principles descriptors. J. Phys. Chem. Lett. 7, 244-249 (2016).

51. Merkle, R., Mastrikov, Y. A., Kotomin, E. A., Kuklja, M. M. \& Maier, J. First principles calculations of oxygen vacancy formation and migration in $\mathrm{Ba}_{1-\mathrm{x}} \mathrm{Sr}_{\mathrm{x}} \mathrm{Co}_{1-\mathrm{y}} \mathrm{Fe}_{\mathrm{y}} \mathrm{O}_{3-\delta}$ Perovskites. J. Electrochem. Soc. 159, B219-B226 (2011).

52. $\mathrm{Zhu}$, Y. et al. $\mathrm{SrNb}_{0.1} \mathrm{Co}_{0.7} \mathrm{Fe}_{0.2} \mathrm{O}_{3-\delta}$ perovskite as a next-generation electrocatalyst for oxygen evolution in alkaline solution. Angew. Chem. Int. Ed. Engl. 127, 3969-3973 (2015).

\section{Acknowledgements}

Financial support for this work was provided by the R. A. Welch Foundation (grants F1529 and F-1319). X.R. and A.M.K. acknowledge support from the Skoltech-MIT Center for Electrochemical Energy Storage. Computations were performed using computational resources from XSEDE and NERSC. The Kratos XPS was funded by the NSF under grant CHE-0618242. 


\section{Author contributions}

R.P.F. and W.G.H. performed the synthesis, X-ray diffraction, iodometric titrations, and electrochemical characterization. A.M.A. performed HAADF-STEM, ABF-STEM, SAED, energy dispersive X-ray measurements, and crystallographic analysis. D.F. performed Mössbauer spectroscopy and provided analysis. X.R. and A.M.K. performed density functional theory computations. C.T.A. and J.T.M. provided reference electrochemical data and intellectual contributions to this work. H.I. assisted with materials synthesis. R. P.F., W.G.H., A.M.A., X.R., A.M.K., K.P.J., and K.J.S. planned the experiments and analyzed the data.

\section{Additional information}

Supplementary Information accompanies this paper at https://doi.org/10.1038/s41467018-05600-y.

Competing interests: The authors declare no competing interests.

Reprints and permission information is available online at http://npg.nature.com/ reprintsandpermissions/
Publisher's note: Springer Nature remains neutral with regard to jurisdictional claims in published maps and institutional affiliations.

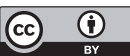

Open Access This article is licensed under a Creative Commons Attribution 4.0 International License, which permits use, sharing, adaptation, distribution and reproduction in any medium or format, as long as you give appropriate credit to the original author(s) and the source, provide a link to the Creative Commons license, and indicate if changes were made. The images or other third party material in this article are included in the article's Creative Commons license, unless indicated otherwise in a credit line to the material. If material is not included in the article's Creative Commons license and your intended use is not permitted by statutory regulation or exceeds the permitted use, you will need to obtain permission directly from the copyright holder. To view a copy of this license, visit http://creativecommons.org/ licenses/by/4.0/.

(C) The Author(s) 2018 